\title{
Investigation of Flavor-Forming Starter Lactococcus lactis subsp. lactis LDTM6802 and Lactococcus lactis subsp. cremoris LDTM6803 in Miniature Gouda-Type Cheeses
}

\author{
Hye Won Lee ${ }^{1}$, In Seon Kim ${ }^{2,3}$, Bum Ju Kil ${ }^{4}$, Eunsol Seo ${ }^{4}$, Hyunjoon Park ${ }^{3}$, Jun-Sang Ham ${ }^{6}$, \\ Yun-Jaie $\mathrm{Choi}^{2,5 *}$, and Chul Sung Huh ${ }^{1,3 *}$ \\ 'Graduate School of International Agricultural Technology, Seoul National University, Pyeongchang 25354, \\ Republic of Korea \\ ${ }^{2}$ Department of Agricultural Biotechnology, Seoul National University, Seoul 08826, Republic of Korea \\ ${ }^{3}$ Institute of Green-Bio Science and Technology, Seoul National University, Pyeongchang 25354, Republic of Korea \\ ${ }^{4}$ WCU Biomodulation Major and Center for Food and Bioconvergence, Seoul National University, Seoul 08826, \\ Republic of Korea \\ ${ }^{5}$ Research Institute of Agriculture and Life Science, Seoul National University, Seoul 08826, Republic of Korea \\ ${ }^{6}$ National Institute of Animal Science, Rural Development Administration, Wanju 55365, Republic of Korea
}

Lactic acid bacteria (LAB) play an important role in dairy fermentations, notably as cheese starter cultures. During the cheese production and ripening period, various enzymes from milk, rennet, starter cultures, and non-starter LABs are involved in flavor formation pathways, including glycolysis, proteolysis, and lipolysis. Among these three pathways, starter LABs are particularly related to amino acid degradation, presumably as the origins of major flavor compounds. Therefore, we used several enzymes as major criteria for the selection of starter bacteria with flavor-forming ability. Lactococcus lactis subsp. lactis LDTM6802 and Lactococcus lactis subsp. cremoris LDTM6803, isolated from Korean raw milk and cucumber kimchi, were confirmed by using multiplex PCR and characterized as starter bacteria. The combinations of starter bacteria were validated in a miniature Gouda-type cheese model. The flavor compounds of the tested miniature cheeses were analyzed and profiled by using an electronic nose. Compared to commercial industrial cheese starters, selected starter bacteria showed lower $\mathrm{pH}$, and more variety in their flavor profile. These results demonstrated that LDTM6802 and LDTM6803 as starter bacteria have potent starter properties with a characteristic flavor-forming ability in cheese.

First published online: June 5, 2020

*Corresponding authors Y.J.C.

Phone: $+82-2-880-4807$ Fax: +82-2-880-7340 E-mail: cyjcow@snu.ac.kr C.S.H.

Phone: +82-33-339-5723 Fax: +82-33-339-5855

E-mail: cshuh@snu.ac.kr

Supplementary data for this paper are available on-line only at http://jmb.or.kr.

pISSN 1017-7825 elSSN 1738-8872

Copyright(C) 2020 by The Korean Society for Microbiology and Biotechnology

\section{Introduction}

Milk and dairy products, including cheeses, are important components of the human diet and play an essential role in meeting nutritional requirements [1]. Gouda cheese is a washed-curd Dutch cheese that is traditionally produced from bovine milk [2-4]. It is soaked in a brine solution and ripened for 1 to 20 months, which improves the taste [5]. The Code of Federal Regulations of the United States specifies a maximum moisture content of $45 \%$ by weight and a minimum $46 \%$ fat content on a dry weight basis for Gouda cheeses.

Starter cultures used in the production of cheeses are typically composed of mesophilic lactic acid bacteria (LAB) having acidification activity, proteolytic activity, and flavor production. [6, 7]. In particular, the Goudatype cheeses are primarily made from Lactococcus lactis subsp. lactis and L. lactis subsp. cremoris, which are principal acid producers [8]. In addition, L. lactis subsp. lactis biovar diacetylactis and/or Leuconostoc spp. are secondary microflora that ferment citrate with the production of $\mathrm{CO}_{2}$, diacetyl, and acetate [9].

As the cheese market has grown, consumers and producers have focused on new types of cheese with unique flavor characteristics [10]. Cheese flavor is a result of complex processes originating from a combination of microbiological, biochemical, and technological aspects. As cheese ripens, the starter culture produces the flavor compounds through carbohydrates fermentation, casein proteolysis, milk fat lipolysis, and non-enzymatic 
reactions [11-13]. Lactose is converted to lactic acid and acetic acid, which decrease the $\mathrm{pH}$ during cheese ripening. The production of these acids contributed to the fresh acidic flavor of the cheese. Moreover, lactic acid can be further metabolized into various flavor compounds, including ethyl esters. The citrate can be converted to acetic acid, diacetyl, acetoin, and butane-2,3-dione [14]. In addition, Lactococcus species produce amino acids from central metabolism and have a well-characterized cell envelope-associated protease that hydrolyzes casein to amino acids [15]. Intracellularly, most amino acids can be converted to $\alpha$-keto acids by aminotransferases. The central intermediate $\alpha$-keto acids can be converted to aldehydes, hydroxyl acids, and CoA-esters by decarboxylase and dehydrogenase [16]. Methyl ketones, secondary alcohols, esters, and lactones can be produced from lipolysis of milk fat [17].

New starter strains of LAB isolated from different milk environments and fermented foods may show good potential for developing improved cheese flavor $[18,19]$. This study focuses on the flavor-forming ability of lactococci strains originated from Gangwon Province in Korea for production of the Gouda-type cheese. To validate the potential of the selected strains as Gouda cheese starters, we confirmed the enzyme distributions related to the flavor compounds by specific polymerase chain reaction (PCR) and analyzed the aroma profiles of miniature cheese models by electronic nose.

\section{Materials and Methods}

\section{Bacterial Strains and Culture Conditions}

Lactococcus lactis subsp. lactis LDTM6802 (KCTC18611P) and Lactococcus lactis subsp. cremoris LDTM6803 (KCTC18612P) were isolated from cucumber kimchi and raw milk products from Gangwon Province, South Korea. Collected kimchi samples were serially diluted 10 -fold using $0.85 \% \mathrm{NaCl}$ solution (Sigma-Aldrich, USA) and homogenized. Serial dilutions were plated on M17 (Difco, USA) supplemented with $0.5 \%$ lactose (GM17) (Difco) agar for lactococci isolation. Inoculated plates were incubated at $30^{\circ} \mathrm{C}$ under aerobic conditions for $48 \mathrm{~h}$. The strains were deposited in the Korean Collection for Type Cultures (KCTC). We used the commercial starter culture CHN-11 (Chr. Hansen, Denmark), which contains Lactococcus lactis subsp. lactis, Lactococcus lactis subsp. cremoris, Lactococcus lactis subsp. lactis biovar diacetylactis, and Leuconostoc subsp. mesenteroides. We isolated Lactococcus lactis subsp. cremoris (CHN-11-3), Lactococcus lactis subsp. lactis biovar diacetylactis (CHN11-1), and Leuconostoc subsp. mesenteroides (CHN-11-48) from CHN-11 starter, as confirmed by 16S rRNA gene sequence analysis. Lactococcus lactis subsp. lactis IL1403 (KCTC3115) was used as a type strain. These strains were cultured in M17 (Difco) supplemented with $0.5 \%$ lactose (GM17) at $30^{\circ} \mathrm{C}$ under aerobic conditions and stored in $20 \%$ glycerol (Sigma-Aldrich) at $-80^{\circ} \mathrm{C}$.

\section{Acidification and Coagulant Activity}

Each strain was inoculated at $1 \%(\mathrm{v} / \mathrm{v})$ in sterilized $10 \%$ skim milk (Oxoid, UK) under aerobic conditions at $30^{\circ} \mathrm{C}$ for $48 \mathrm{~h}$. The acidification activity was measured by using the Orion Star A211 pH-Meter (Thermo Scientific, USA) after 6 and $48 \mathrm{~h}$ incubation. The coagulant activity was evaluated by the appearance of a coagulum of $10 \%$ skimmed milk, after manually tilting the tube [20].

\section{Multiplex PCR}

The multiplex PCR assay was used to detect the genes for enzymes involved in flavor-forming pathways. The primers were designed manually by using the Primer-BLAST tool of National Center for Biotechnology Information (NCBI, USA) and were commercially obtained (Bioneer, Korea). Amplification was performed on a PCR system in a $20 \mu \mathrm{l}$ reaction mixture consisting of i-Taq 2X PCR Master Mix Solution (iNtRON, Korea) with one colony of each streaking plate. The following PCR program was used for 30 cycles: $30 \mathrm{sec}$ at $95^{\circ} \mathrm{C}, 20 \mathrm{sec}$ at 41 $43^{\circ} \mathrm{C}$, and $2.2 \mathrm{~min}$ at $72^{\circ} \mathrm{C}$. The amplified products of each group were run on $1.5 \%$ agarose in $1 \times$ TAE buffer at $70 \mathrm{v}$ for $40 \mathrm{~min}$.

\section{Glutamate Dehydrogenase (GDH) Assay}

Each strain was inoculated at $1 \%(\mathrm{v} / \mathrm{v})$ in $10 \mathrm{ml}$ of media and incubated at $30^{\circ} \mathrm{C}$ under aerobic conditions for $18 \mathrm{~h}$. The cells were harvested by centrifugation, washed twice with phosphate-buffered saline (Mediatech Inc., USA), and added to microtubes containing $2.0 \mathrm{~g}$ of Zirconia/silica beads ( $0.1 \mathrm{~mm}$ dia., BioSpec Products, USA). Each of the cell-free extracts (CFEs) was obtained in the following manner: two cycles of 30-sec disruption at the highest speed of the disruptor (Mini-Beadbeater-16, BioSpec Products) and 1 min of cooling on ice. The CFEs were stored at $-20^{\circ} \mathrm{C}$ until further use [21].

The GDH activities of the CFEs were analyzed by using a commercial colorimetric glutamic acid assay (RBiopharma, Germany). The reaction mixture contained $80 \mu \mathrm{l}$ of distilled water, $80 \mu \mathrm{l}$ of potassium phosphate/ triethanolamine buffer (pH 8.6), $40 \mu \mathrm{l}$ of $100 \mathrm{mM}$ of L-glutamic acid (Sigma-Aldrich), $40 \mu$ lof iodonitrotetrazolium, and $40 \mu \mathrm{l}$ of NAD-diaphorase ( $600 \mu \mathrm{l}$ in total). After the addition of $60 \mu \mathrm{l}$ of CFE to the reaction mixture, 200- $\mu \mathrm{l}$ aliquots of the mixture were immediately distributed to each of 3 wells and incubated for $3 \mathrm{~h}$ at $30^{\circ} \mathrm{C}$ and the absorbance was measured at $492 \mathrm{~nm}[8]$.

\section{Growth and Autolysis Abilities}

Growth curves were obtained for selected strains cultivated at $30^{\circ} \mathrm{C}$ with $1 \%(\mathrm{v} / \mathrm{v})$ inoculation in GM17. The bacterial concentrations were determined by measuring the absorbance at $600 \mathrm{~nm}$ by using a spectrophotometer. In addition, the selected strain was incubated at $30^{\circ} \mathrm{C}$ with $1 \%(\mathrm{v} / \mathrm{v})$ inoculation in $\mathrm{GM} 17$ and the $\mathrm{pH}$ change over time was measured by pH meter. API CHL 50 and API ZYM (BioMérieux, France) were used for carbohydrate 
fermentation and enzymatic profiling, respectively. The API tests were performed according to the manufacturer's instructions.

The rate of cell autolysis was measured according to the method of El Soda et al. [22]. Briefly, the different cell cultures were harvested by centrifugation $\left(8,000 \mathrm{~g}, 15 \mathrm{~min}, 4^{\circ} \mathrm{C}\right)$ and washed twice with $0.85 \% \mathrm{NaCl}$. The obtained pellet was then resuspended in $0.01 \mathrm{M}$ phosphate buffer ( $\mathrm{pH}$ 5.5) containing $0.5 \mathrm{M} \mathrm{NaCl}$. The cell suspension was initially adjusted at an optical density of 0.9 to 1.0 at $600 \mathrm{~nm}$ by using spectrophotometer.

\section{Manufacture of Miniature Cheese Models}

The miniature cheese models were manufactured according to Hynes et al. [23]. Three miniature cheeses, two control groups and one test group were produced by different starter cultures. The starter strains were inoculated into sterile $10 \%$ skim milk. After $18 \mathrm{~h}$ of incubation at $30^{\circ} \mathrm{C}$, each culture was mixed as control 1 (CHN-11-3, IL1403), control 2 (CHN-11-3, IL1403, CHN-11-1, and CHN-11-48), and test (LDTM6802 and LDTM6803) groups. Liquid rennet extract of bovine origin (STD PLUS 290, Chr. Hansen) was used. The cheeses were produced in bottles with $400 \mathrm{ml}$ of milk $\left(30^{\circ} \mathrm{C}\right)$, inoculated starter $(2 \%, \mathrm{v} / \mathrm{v})$, and $80 \mu \mathrm{l}$ of rennet. The bottles were immediately covered, manually inverted three times, and finally incubated in a water bath at $30^{\circ} \mathrm{C}$. After coagulation, the bottles were maintained in a water bath. The coagulum was cut with sterile disposable steel tools. The mixture of whey-curd particles was agitated for $20 \mathrm{~min}$ in a mechanical stirrer by inversion of the bottles. Approximately $40 \%(160 \mathrm{ml})$ of the whey was discarded and replaced by an equal volume of sterile water at $30^{\circ} \mathrm{C}$. Curd washing was completed by stirring for $10 \mathrm{~min}$ as described above.

The bottles were centrifuged at $320 \mathrm{~g}$ for $10 \mathrm{~min}$ at room temperature to remove most of the aqueous phase. Subsequently, the curd was transferred to sterile cylindrical $150 \mathrm{ml}$ recipients, and re-centrifuged at 1,400 g for $1 \mathrm{~h}$. The whey was then discarded and the curd was inverted in the same container. A final centrifugation was performed at 1,400 g for $30 \mathrm{~min}$. The miniature cheeses were stored in sterile containers and salted by pouring 32 $\mathrm{ml}$ of sterile saturated brine $(330 \mathrm{~g} / \mathrm{L}$ of NaCl, $\mathrm{pH}$ adjusted to 5.4$)$ at $10^{\circ} \mathrm{C}$ into the same containers. After $5 \mathrm{~min}$, the brine was removed, and the miniature cheeses were ripened at $10^{\circ} \mathrm{C}$ for 28 days [24].

\section{Evaluation of Flavor Profile by Electronic Nose}

The Heracles II Analyzer/GC E-Nose (Alpha M.O.S, France), consisting of a dual-column flash gaschromatograph coupled with a Combi PAL Auto-Sampler System (CTC Analytics AG, Switzerland), was used. The analysis was performed according to the manufacturer's instructions (Alpha M.O.S). Gas samples from the headspace after pre-incubation for $20 \mathrm{~min}$ at $70^{\circ} \mathrm{C}$ were collected from each $10 \mathrm{ml}$ vial containing $1 \mathrm{~g}$ of cheese and delivered by the auto-sampler to an inlet injector in which the compounds were flash evaporated. After passing through a pre-concentration TENAX adsorbent trap, the volatiles carried by the hydrogen are equally sent to two capillary chromatographic columns. The two columns have different polarities (one column was apolar, GC1\#: DB-5, and the other column had medium polarity, GC\#2: DB-WAX), and various volatile compounds were simultaneously separated on both of these columns and detected by flame ionization detectors (FID) working in parallel. The following analytical conditions for automatic gas injection with a 2.5 -ml HS syringe from the headspace were used: quantity of sample: $1 \mathrm{~g}$ in a $10 \mathrm{ml}$ vial, sample incubation $20 \mathrm{~min}$ at $70^{\circ} \mathrm{C}$ (agitation speed $500 \mathrm{rpm}$, agitation on $5 \mathrm{sec}$, agitation off $2 \mathrm{sec}$, flushing time $90 \mathrm{sec}$ ), syringe temperature $80^{\circ} \mathrm{C}$, fill speed $500 \mu \mathrm{l} / \mathrm{sec}$, injection volume $5,000 \mu \mathrm{l}$, injection speed $125 \mu \mathrm{l} / \mathrm{s}$, injection temperature $200^{\circ} \mathrm{C}$, injection pressure $10 \mathrm{kPa}$, injection time $45 \mathrm{sec}$, trap temperature $50^{\circ} \mathrm{C}$, trap pre-heating temperature $35^{\circ} \mathrm{C}$, column temperature program $50^{\circ} \mathrm{C}$ (initial, hold time $2 \mathrm{sec}$ ) up to $250^{\circ} \mathrm{C}(21 \mathrm{sec})$ with an increment of $1^{\circ} \mathrm{C} / \mathrm{sec}$ to $80^{\circ} \mathrm{C}$ and an increment of $3^{\circ} \mathrm{C} / \mathrm{sec}$ to $250^{\circ} \mathrm{C}$, with a detector temperature of $260^{\circ} \mathrm{C}$. The two chromatograms were analyzed by AroChemBase specialized software (Alpha M.O.S) for sensory descriptions.

\section{Statistical Analysis}

All data were statistically analyzed using Graph-Pad Prism software version 5.01 (Graph-Pad Software, USA). The statistical significance of the differences was determined by one-way analysis of variance (ANOVA) followed by Tukey's post hoc test. Differences were considered significant at $p<0.05$.

\section{Results}

\section{Analysis of Lactic Acid Bacteria for Cheese Starter}

The main role of starter bacteria in cheese manufacturing is to provide coagulant activity and rapid acidification. CHN-11-1, CHN-11-3, LDTM6802, and LDTM6803 strains had positive coagulant activity at 24 and $48 \mathrm{~h}$ (Table 1). According to the acid production monitoring after 6 and $48 \mathrm{~h}$, the Chr. Hansen starter strains and control strains showed a $\mathrm{pH}$ value from 6.05 to 6.15 at $6 \mathrm{~h}$ and from 4.39 to $5.72 \mathrm{at} 48 \mathrm{~h}$. That means the CHN11-1 and CHN-11-3 strains played roles as a starter culture for the acidification of milk. The LDTM6802 and LDTM6803 strains showed higher acid production than these strains at $6 \mathrm{~h}$ (Table 1).

To investigate the flavor-forming ability of lactic acid bacteria by carbohydrate, protein, and fat fermentation, LDTM6802 and LDTM6803 were analyzed by multiplex PCR and GDH activity (Table 1). The CHN-11-1 and IL1403 strains encoded all target genes except citP, whereas CHN-11-3 encoded only bcaT, and CHN-11-48 encoded none of the target genes. The LDTM6802 encoded adhE, bcaT, araT, estA, and adh genes, and LDTM6803 encoded $b c a T$ and $k d c A$ genes (Table 1). The level of NAD-dependent GDH was also analyzed (Table 1). The LDTM6802 had a significant level of GDH activity compared to that of IL1403, CHN-11-1, and CHN-11-3. In addition, the GDH activity of LDTM6803 showed higher activity than that of IL1403, CHN-11-1, and $\mathrm{CHN}-11-3$. Furthermore, to confirm the production ability of the flavor compounds, the carbohydrate 
Table 1. The summary of in vitro phenotypic and genotypic characteristics of the most promising cheese starter LAB with flavor-forming ability.

\begin{tabular}{|c|c|c|c|c|c|c|c|c|c|c|c|c|}
\hline \multirow[t]{2}{*}{ Source } & \multirow[t]{2}{*}{ Target bacteria } & \multicolumn{2}{|c|}{$\begin{array}{c}\text { Coagulant } \\
\text { activity } \\
\end{array}$} & $\mathrm{pH}$ & \multicolumn{7}{|c|}{ Target gene $^{\mathrm{a}}$} & \multirow{2}{*}{$\begin{array}{c}\text { GDH } \\
\text { activity } \\
(\mathrm{U})^{\#}\end{array}$} \\
\hline & & $24 \mathrm{~h}$ & $48 \mathrm{~h}$ & $6 \mathrm{~h} 48 \mathrm{~h}$ & adhE & $b c a T$ & $\operatorname{araT}$ & est $A$ & $a d h$ & citP & $k d c A$ & \\
\hline \multirow{4}{*}{$\begin{array}{l}\text { Chr. } \\
\text { Hansen } \\
\text { (Control) }\end{array}$} & $\begin{array}{l}\text { Lactococcus lactis subsp. lactis } \\
\text { IL1403 }\end{array}$ & - & - & 6.065 .27 & + & + & + & + & + & - & + & $\begin{array}{c}0.157 \\
\pm 0.026\end{array}$ \\
\hline & $\begin{array}{l}\text { Lactococcus lactis subsp. lactis } \\
\text { biovar diacetylactics CHN-11-1 }\end{array}$ & ++ & ++ & 6.154 .39 & + & + & + & + & + & + & + & $\begin{array}{c}0.151 \\
\pm 0.004\end{array}$ \\
\hline & $\begin{array}{l}\text { Lactococcus lactis subsp. } \\
\text { cremoris } \mathrm{CHN}-11-3\end{array}$ & + & ++ & 6.104 .57 & - & + & - & - & - & - & - & $\begin{array}{c}0.134 \\
\pm 0.012\end{array}$ \\
\hline & $\begin{array}{l}\text { Leuconotocpseudomesenteroides } \\
\text { CHN-11-48 }\end{array}$ & - & - & 6.055 .72 & - & - & - & - & - & - & - & $\begin{aligned} & 0.230 \\
\pm & 0.010^{* *}\end{aligned}$ \\
\hline $\begin{array}{l}\text { Cucumber } \\
\text { kimchi }\end{array}$ & $\begin{array}{l}\text { Lactococcus lactis subsp. lactis } \\
\text { LDTM } 6802\end{array}$ & + & ++ & 5.764 .54 & + & + & + & + & + & - & - & $\begin{array}{c}0.224 \\
\pm 0.028^{*}\end{array}$ \\
\hline Raw milk & $\begin{array}{l}\text { Lactococcus lactis subsp. } \\
\text { cremoris LDTM } 6803\end{array}$ & ++ & ++ & 5.274 .28 & - & + & - & - & - & - & + & $\begin{array}{c}0.211 \\
\pm 0.020\end{array}$ \\
\hline
\end{tabular}

Target gene: $a d h E$, bifunctional aldehyde/alcohol dehydrogenase; $b c a T$, branched-chain aminostransferase; araT, aromatic aminotransferase; est $A$, esterase $\mathrm{A} ; a d h$, alcohol dehydrogenase; $c i t P$, citrate permease; $k d c A$, keto acid decarboxylase.

${ }^{\#} p$-value were analyzed by one-way analysis of variance (ANOVA) $\left({ }^{*} p \leq 0.05 ;{ }^{* *} p \leq 0.01\right)$.

fermentation and enzymatic patterns were assayed with the Chr. Hansen starter and selected strains (Fig. 1). The LDTM6802 and LDTM6803 strains had the strongest carbohydrate fermentation activity, and the LDTM6802 showed a variety of enzymatic patterns compared to those of IL1403, CHN-11-1, CHN-11-3, and CHN-11-48. Overall, the selected strains showed similar genotypic characteristics and better phenotypic characteristics than the Chr. Hansen starters.

\section{Growth and Fermentation Properties}

Autolysis can accelerate the production of metabolites by proteolysis and lipolysis through an early release of intracellular enzymes during cheese ripening. To confirm the growth pattern and enzyme release ability, growth, $\mathrm{pH}$ curves and autolysis were analyzed in this study. All strains reached their maximum growth within $24 \mathrm{~h}$ and L. lactis subsp. lactis strains were relatively stable up to $48 \mathrm{~h}$ compared to L. lactis subsp. cremoris strains (Fig. 2A). All strains except IL1403 showed a sharp decrease in $\mathrm{pH}$ during $12 \mathrm{~h}$ incubation, while LDTM 6802 had the lowest pH (Fig. 2B). In addition, LDTM6802 and LDTM6803 strains had high autolysis activity compared to that of control IL1403 and CHN-11-3 (Fig. 2C). The $\mathrm{pH}$ of the control and test miniature cheeses dropped dramatically at 1 week of ripening, and after that the control cheeses decreased above $\mathrm{pH} 5$, while test cheese dropped to below $\mathrm{pH}$ 5. In addition, the test cheese had a stable $\mathrm{pH}$ from the beginning of the ripening period (Fig. 2D).

\section{Flavor Compound Analysis of Miniature Gouda-Type Cheese}

To evaluate the flavor of miniature Gouda-type cheese by the selected strains, control and test miniature cheeses were manufactured. All miniature cheeses were ripened at $10^{\circ} \mathrm{C}$ for 4 weeks and analyzed using an electronic nose. The test miniature cheeses were found to have more varied flavor profiles than the control miniature cheeses. After 4 weeks, the ripened cheeses of the control and test groups at $10^{\circ} \mathrm{C}$ were detected with some flavor compounds, such as acetoin, butane-2,3-dione, ethanol, formic acid, 1,3-dimethylcyclohexane, and 3-buten-2-

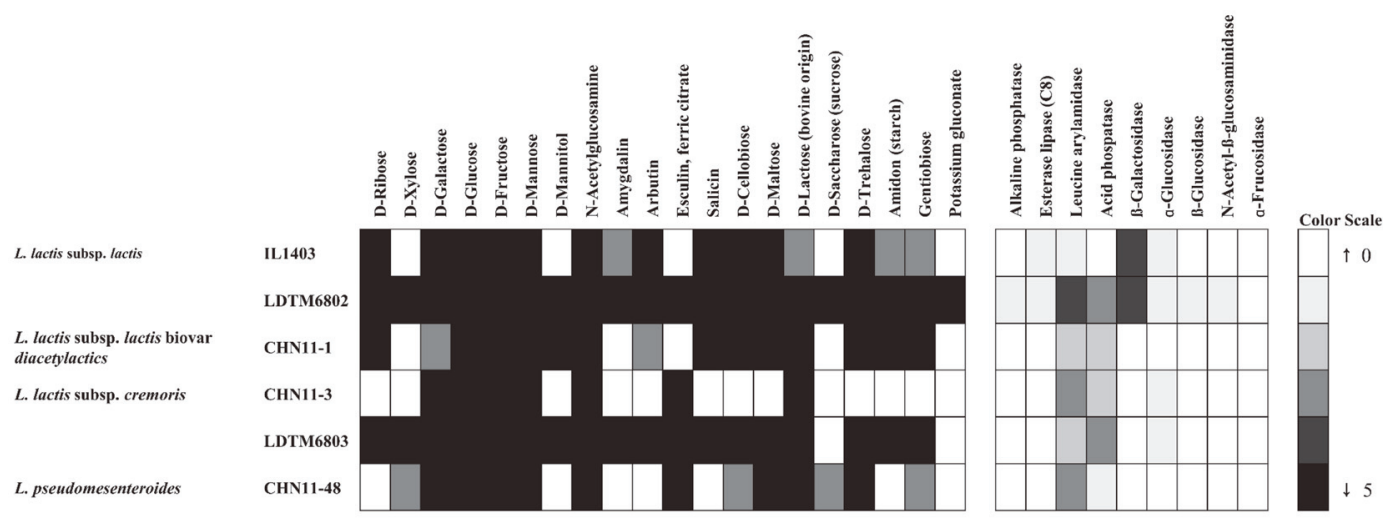

Fig. 1. The carbohydrate fermentation and enzymatic patterns of selected L. lactis subsp. lactis strains and L. lactis subsp. cremoris strains were assessed compared to control strains by API CHL 50 and API ZYM kits. In the API CHL 50, black and white represent positive and negative activity, respectively, and gray means weak activity. The API ZYM are shown in a black-white color scale ( 0 to 5 ) according to the manufacturer's instructions. 
A

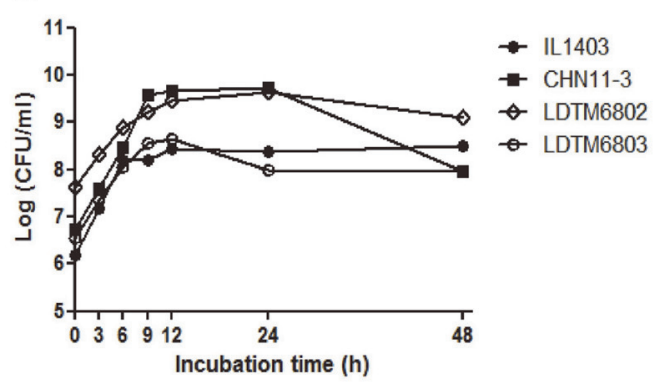

C

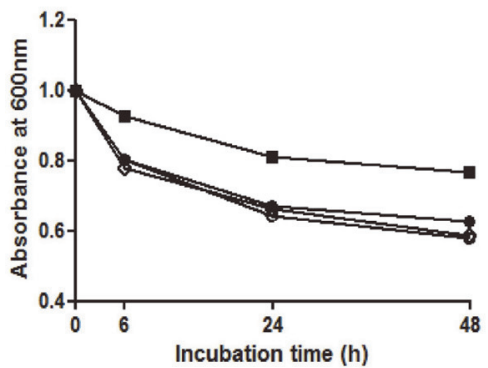

B

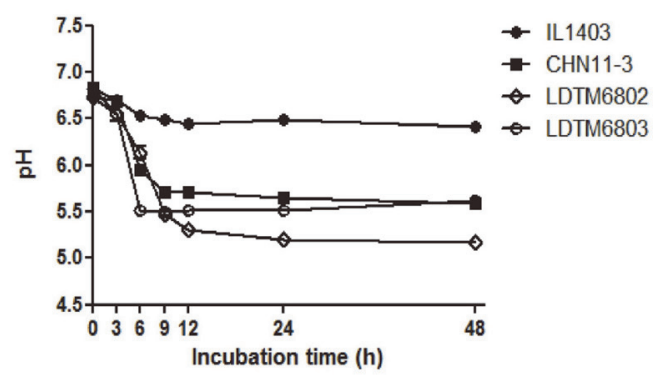

D

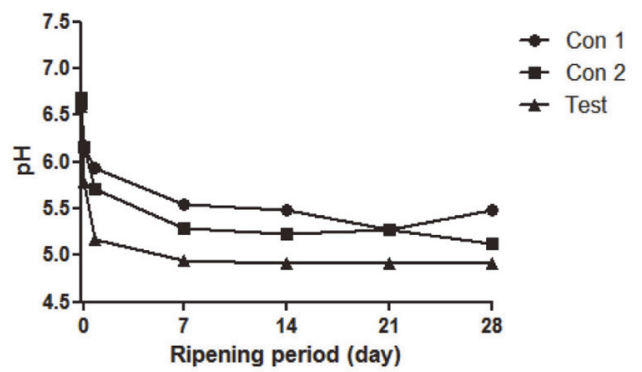

Fig. 2. Growth and fermentation properties of the tested strains and $\mathrm{pH}$ change of miniature cheese products. (A) bacterial growth curves. (B) $\mathrm{pH}$ change of the strains. (C) autolysis activity. (D) $\mathrm{pH}$ change of the miniature cheese products during ripening. Data are presented as means \pm SEMs.

one (Table 2). Among these compounds, the main peak of 3-buten-2-one, a small peak of acetoin, and formic acid were observed in the control group for 4 weeks. (Figs. 3A and 3B). The intensity of the compound peaks varied with the length of the ripening period. In control 1,3-buten-2-one was the highest at 2 weeks of ripening and then decreased. Also, 3-buten-2-one in control 2 was highest at 3 weeks and then decreased. On the other hand, the ripened cheese of the test group showed additional peaks of enflurane, isopropyl isothiocyanate, methylbutanone, methyl isothiocyanate, 2-methyl-1-propanol, and 2,4-dimethylfuran, but did not show 3-buten-2-one. At 2 weeks of ripening, 2,4-dimethylfuran increased and decreased, and at 4 weeks, methyl isothiocyanate increased (Fig. 3C). Therefore, L. lactic subsp. lactis LDTM6802 and L. lactis subsp. cremoris LDTM6803 produced more flavor compounds compared to control cheese starter strains on the last ripening day.

The results demonstrated that the cheeses have buttery, sweet, savory, alcoholic, and perfumery flavors, with flavor compounds such as acetoin, butane-2,3-dione, 3-buten-2-one, formic acid, ethanol, and 1,3-

Table 2. Different flavor profiling and expected sensory descriptors from $10^{\circ} \mathrm{C}$ ripened miniature cheese by an electronic nose.

\begin{tabular}{|c|c|c|c|c|}
\hline \multicolumn{2}{|c|}{ Chemical names } & \multirow{2}{*}{ Formula } & \multirow{2}{*}{ Sensory descriptors } & \multirow{2}{*}{ Reference } \\
\hline Control groups & Test group & & & \\
\hline Acetoin & Acetoin & $\mathrm{C}_{4} \mathrm{H}_{8} \mathrm{O}_{2}$ & Butter, Coffee, Creamy & Arochembase $^{\mathrm{a}}$ \\
\hline Butane-2,3-dione & Butane-2,3-dione & $\mathrm{C}_{4} \mathrm{H}_{6} \mathrm{O}_{2}$ & $\begin{array}{l}\text { Butter, Caramelized, Creamy, } \\
\text { Fruity, Pineapple }\end{array}$ & Arochembase \\
\hline Ethanol & Ethanol & $\mathrm{C}_{2} \mathrm{H}_{6} \mathrm{O}$ & Alcoholic, Ethanol, Pungent, Sweet & Arochembase \\
\hline Formic acid & Formic acid & $\mathrm{CH}_{2} \mathrm{O}_{2}$ & Savory & FEMA $^{\mathrm{b}}$ \\
\hline 1,3-Dimethylcyclohexane & 1,3-Dimethylcyclohexane & $\mathrm{C}_{8} \mathrm{H}_{16}$ & Perfumery & Arochembase \\
\hline \multirow[t]{7}{*}{ 3-Buten-2-one } & 3-Buten-2-one & $\mathrm{C}_{4} \mathrm{H}_{6} \mathrm{O}$ & Sweet & Arochembase \\
\hline & Enflurane & $\mathrm{C}_{3} \mathrm{H}_{2} \mathrm{CIF}_{5} \mathrm{O}$ & Etheral, Pungent & Arochembase \\
\hline & Isopropyl isothiocyanate & $\mathrm{C}_{4} \mathrm{H}_{7} \mathrm{NS}$ & Savory & FEMA \\
\hline & Methylbutanone & $\mathrm{C}_{5} \mathrm{H}_{10} \mathrm{O}$ & Camphor & Arochembase \\
\hline & Methyl isothiocyanate & $\mathrm{C}_{2} \mathrm{H}_{3} \mathrm{NS}$ & Nauseating, Toxic smell & Duque et al. 2001 \\
\hline & 1-Propanol, 2-methyl- & $\mathrm{C}_{4} \mathrm{H}_{10} \mathrm{O}$ & $\begin{array}{l}\text { Alcoholic, Bitter, Chemical, Glue, } \\
\text { Leek, Licorice, Solvent, Winey }\end{array}$ & Arochembase \\
\hline & 2,4-Dimethylfuran & $\mathrm{C}_{6} \mathrm{H}_{8} \mathrm{O}$ & Onion, Galic, Leek & Villière et al. 2015 \\
\hline
\end{tabular}

${ }^{a}$ Database provided by electronic nose manufacturer (Alpha M.O.S, France) which is linked with NIST database (http:// webbook.nist.gov/chemistry).

${ }^{\mathrm{b}}$ FEMA: Flavor \& Extract Manufacturers Association. 
A

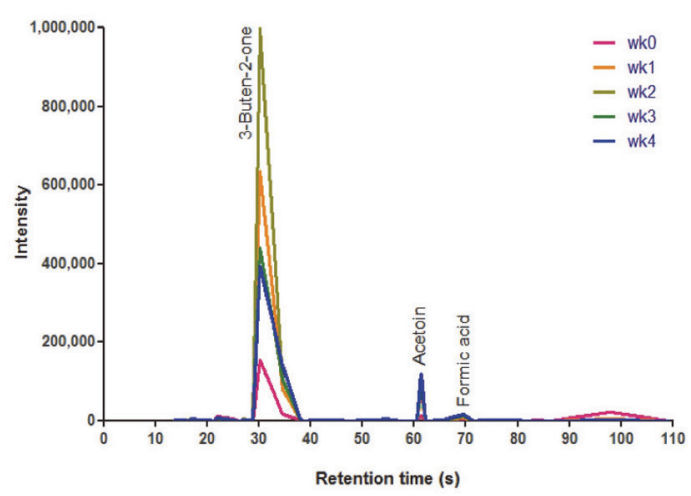

B

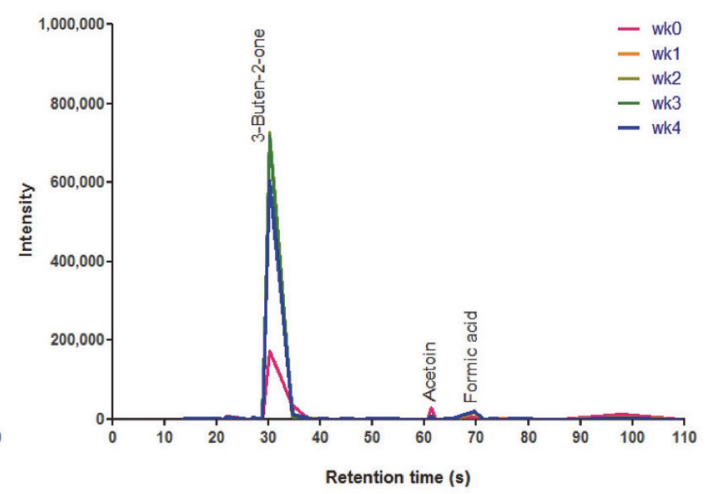

C

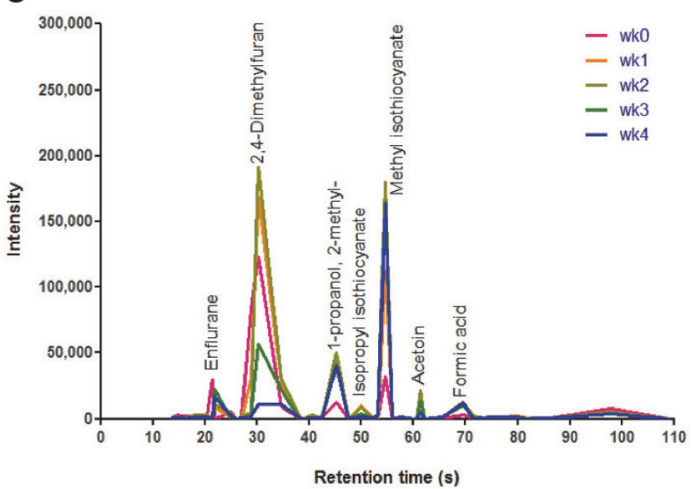

Fig. 3. Measurement of representative flavor compounds of $10^{\circ} \mathrm{C}$ ripened miniature cheese products. (A) control 1. (B) control 2. (C) test cheese.

dimethylcyclohexane (Table 2). In addition, the cheeses produced with LDTM6802 and LDTM6803 have floral, vegetable, bitter, camphor, and almond flavors with flavor compounds such as 3-formythiophene, 2-methyl-1propanol, methylbutanone, and furfural.

\section{Discussion}

Cheese and cheese starter culture-related studies are constantly being conducted worldwide [25-28]. One of the most important cheese starter abilities is curd formation in milk by acid production [18, 29]. Rapid growth, acidification ability, autolysis ability, carbohydrate fermentation pattern, and enzymatic profile are also selection criteria [7]. By using multiplex PCR assay, the $a d h E, b c a T$, araT, est $A$, $a d h$, citP, and $k d c A$ genes were detected in the selected strains. LDTM 6802 had these genes, but did not have citP. The citP gene was not detected in the selected bacteria, but the $k d c A$ gene was found in LDTM6803. The absence of the citP gene in isolates was consistent with the findings of previous studies $[9,30]$. According to Liu et al. [31], the $k d c A$ enzyme activity was only found in non-dairy lactococcal strains. In addition, the GDH activity, carbohydrate fermentative pattern, pH stability, and enzymatic profiling results showed selected probiotic strains can utilize more than the control strain.

Cheese flavors are produced through a complex process. According to the Component Balance Theory of Cheese Flavor, a cheese flavor result is an accurate balance and concentration of a wide variety of volatile flavor compounds [11]. The flavor of cheese varies depending on the cheese type, and even the same type of cheese varies in flavor depending on the starter bacteria and the ripening conditions [32]. According to Smit et al. [16], the flavor components of Gouda cheese are mainly derived from amino acids such as 3-methylbutanal, 3methylbutanol, methanethiol, dimethylsulphide, 2-methylporpanol and dimethyltrisulphide. Additionally, there are other compounds, such as diacetyl, ketones, aldehydes, and fatty acids. As a result, the tested miniature Gouda cheeses have malty, cabbage, alcoholic, fruity, sweet, buttery, and sulphurous flavors. Methylbutanone and 2methyl-1-propanol are typically derived from the branched-chain amino acids leucine and valine, respectively [33]. These flavor compounds demonstrated that the miniature cheeses produced by LDTM6802 and LDTM6803 have a characteristic flavor profile, and that starter bacteria play an important role in the characteristic flavor compounds and flavor intensity of cheese.

In this study, starter strains originated from Gangwon Province were assessed for their flavor-forming ability and validated in a miniature Gouda-type cheese model. Generally, Gouda-type cheese is ripened for a length of time ranging from more than two months to several years [32]. Long-term cheese ripening in the laboratory has 
limits; thus, it is also necessary to shorten the ripening period. Starter bacteria affect flavor formation at least 2 to 3 weeks after cheese production [24]. According to Ur-Rehman et al. [24], miniature cheeses require about 28 days for ripening. Long-term experiments with large-scale Gouda-type cheese production are needed to evaluate the actual flavor formation, and the flavor mechanisms by starter bacteria should be further investigated. The evaluation approach in this study can be used to screen starter bacteria with flavor formation ability and can also be applied to further develop Korean cheese technology and industry.

\section{Acknowledgments}

This research was supported by the Basic Science Research Program through the National Research Foundation of Korea (NRF) funded by the Ministry of Education (No. 2016936920 [Yun-Jaie Choi]). This work was also supported by the Korea Institute of Planning and Evaluation for Technology in Food, Agriculture, Forestry and Fisheries (IPET) through Agri-Bio Industry Technology Development Program, funded by the Ministry of Agriculture, Food and Rural Affairs (MAFRA) (No. 316005-5 [Chul Sung Huh]) and was carried out with the support of "Cooperative Research Program for Agriculture Science and Technology Development (No. PJ01354402 [Chul Sung Huh])” Rural Development Administration, Republic of Korea.

\section{Conflict of Interest}

The authors have no financial conflicts of interest to declare.

\section{References}

1. Brown-Riggs C. 2016. Nutrition and health disparities: The role of dairy in improving minority health outcomes. Int. J. Environ. Res. Public Health 13: 28

2. van den Berg G, Meijer WC, Düsterhöft EM, Smit G. 2004. Gouda and related cheeses. Cheese: Chemistry. Physics Microbiology 2: 103-140.

3. Mellgren J. 2005. All cheese considered: Gouda, Bus. Source Complete 26: 11-19.

4. Jung HJ, Ganesan P, Lee SJ, Kwak HS. 2013. Comparative study of flavor in cholesterol-removed Gouda cheese and Gouda cheese during ripening. J. Dairy Sci. 96: 1972-1983.

5. Toelstede S, Hofmann T. 2008. Sensomics mapping and identification of the key bitter metabolites in Gouda cheese. J. Agric. Food Chem. 56: 2795-2804.

6. Frece J, Cvrtila J, Topić I, Delaš F, Markov K. 2014. Lactococcus lactis ssp. lactis as potential functional starter culture. Food Technol. Biotechnol. 52: 489-494.

7. Ayad EHE, Verheul A, Wouters JTM, Smit G. 2000. Application of wild starter cultures for flavor development in pilot plant cheese making. Int. Dairy J. 10: 169-179.

8. Kieronczyk A, Skeie S, Langsrud T, Yvon M. 2003. Cooperation between Lactococcus lactis and nonstarter Lactobacilli in the formation of cheese aroma from amino acids. Appl. Environ. Microbiol. 69: 734-739.

9. Drici H, Gilbert C, Kihal M, Atlan D. 2010. Atypical citrate fermenting Lactococcus lactis strains isolated from dromedary's milk. J. Appl. Microbiol. 108: 647-657.

10. Silva HLA, Balthazar CF, Esmerino EA, Vieira AH, Cappato LP, Neto RPC, et al. 2017. Effect of sodium reduction and flavor enhancer addition on probiotic Prato cheese processing. Food Res. Int. 99: 247-255.

11. Singh TK, Drake MA, Cadwallader KR. 2003. Flavor of cheddar cheese: A chemical and sensory perspective. Comp. Rev. Food Sci. 2: $139-162$

12. Gutiérrez-Méndez N, Vallejo-Cordoba B, González-Córdova AF, Nevárez-Moorillón GV, Rivera-Chavira B. 2008. Evaluation of aroma generation of Lactococcus lactis with an electronic nose and sensory analysis. J. Dairy Sci. 91: 49-57.

13. Zheng X, Liu F, Shi X, Wang B, Li K, Li B, et al. 2018. Dynamic correlations between microbiota succession and flavor development involved in the ripening of Kazak artisanal cheese. Food Res. Int. 105: 733-742.

14. Starrenburg MJC, Hugenholtz J. 1991. Citrate fermentation by Lactococcus and Leuconostoc spp. Appl. Environ. Microbiol. 57: 35353540 .

15. Tjwan Tan P, Poolman B, Konings W. 1993. Proteolytic enzymes of Lactococcus lactis. J. Dairy Res. 60: 269-286.

16. Smit G, Smit BA, Engels WJ. 2005. Flavour formation by lactic acid bacteria and biochemical flavour profiling of cheese products. FEMS Microbiol. Rev. 29: 591-610.

17. Molimard P, Spinnler HE. 1996. Review: Compounds involved in the flavor of surface mold-ripened cheeses: Origins and properties. J. Dairy Sci. 79: 169-184

18. Cogan TM, Barbosa M, Beuvier E, Bianchi-Salvadori B, Cocconcelli PS, Fernandes I, et al. 1997. Characterization of the lactic acid bacteria in artisanal dairy products. J. Dairy Res. 64: 409-421.

19. Ayad EHE, Verheul A, de Jong C, Wouters JTM, Smit G. 1999. Flavour forming abilities and amino acid requirements of Lactococcus lactis strains isolated from artisanal and non-dairy origin. Int. Dairy J. 9: 725-735.

20. Randazzo CL, De Luca S, Todaro A, Restuccia C, Lanza CM, Spagna G, et al. 2007. Preliminary characterization of wild lactic acid bacteria and their abilities to produce flavor compounds in ripened model cheese system. J. Appl. Microbiol. 103: 427-435.

21. Peralta GH, Bergamini CV, Hynes ER. 2016. Aminotransferase and glutamate dehydrogenase activities in lactobacilli and streptococci. Braz. J. Microbiol. 47: 741-748.

22. El Soda M, Ahmed N, Omran N, Osman G, Morsi A. 2003. Isolation, identification and selection of lactic acid bacteria cultures for cheese making. Emir. J. Agric. Sci. 15: 51-71.

23. Hynes E, Ogier JC, Delacroix-Buchet A. 2000. Protocol for the manufacture of miniature washed-curd cheeses under controlled microbiological conditions. Int. Dairy J. 10: 673-681.

24. Shakeel-Ur-Rehman, F PF, McSweeney PLH, Madkor SA, Farkye NY. 2001. Alternatives to pilot plant experiments in cheese-ripening studies. Int. J. Dairy Technol. 54: 121-126.

25. Bosset JO, Gauch R. 1993. Comparison of the volatile flavour compounds of six european 'AOC' cheeses by using a new dynamic headspace GC-MS method. Int. Dairy J. 3: 359-377.

26. Thage BV, Houlberg U, Ardö Y. 2004. Amino acid transamination in permeabilised cells of Lactobacillus helveticus, Lb. paracasei and Lb. danicus. J. Dairy Res. 71: 461-470.

27. Di Cagno R, Quinto M, Corsetti A, Minervini F, Gobbetti M. 2006. Assessing the proteolytic and lipolytic activities of single strains of mesophilic lactobacilli as adjunct cultures using a caciotta cheese model system. Int. Dairy J. 16: 119-130. 
28. Lacroix N, St-Gelais D, Champagne CP, Fortin J, Vuillemard JC. 2010. Characterization of aromatic properties of old-style cheese starters. J. Dairy Sci. 93: 3427-3441.

29. Ong L, Henriksson A, Shah NP. 2006. Development of probiotic Cheddar cheese containing Lactobacillus acidophilus, Lb. casei, Lb. paracasei and Bifidobacterium sp. and influence of these bacteria on proteolytic patterns and production of organic acid. Int. Dairy J. 16: 446-456.

30. Exterkate FA, Lagerwerf FM, Haverkamp J, van Schalkwijk S. 1997. The selectivity of chymosin action on as1- and $\beta$-caseins in solution is modulated in cheese. Int. Dairy J. 7:47-54.

31. Liu SQ, Holland R, Crow VL. 2001. Purification and properties of intracellular esterases from Streptococcus thermophilus. Int. Dairy J. 11: 27-35.

32. Van Leuven I, Van Caelenberg T, Dirinck P. 2008. Aroma characterization of Gouda-type cheeses. Int. Dairy J. 18: 790-800.

33. Helinck S, Le Bars D, Moreau D, Yvon M. 2004. Ability of thermophilic lactic acid bacteria to produce aroma compounds from amino acids. Appl. Environ. Microbiol. 70: 3855-3861. 